\title{
Evaluation of the Resource Use Efficiencies of Small-Scale Vertical Hydroponic Structures against Growing Plants in Soil
}

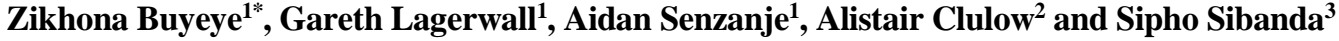 \\ ${ }^{1}$ Bioresources Engineering Programme, School of Engineering, University of Kwa Zulu-Natal, Pietermaritzburg 3209, \\ South Africa \\ ${ }^{2}$ Department of Agrometereology, University of Kwa Zulu-Natal, Pietermaritzburg 3209, South Africa \\ ${ }^{3}$ Institute of Agricultural Engineering, Agricultural Research Council, Pretoria 0184, South Africa \\ *For correspondence: z.buyeye@yahoo.com \\ Received 27 March 2021; Accepted 15 November 2021; Published 30 January 2022
}

\begin{abstract}
The aim of this research was to investigate the use of small-scale vertical farming structures as an alternative to improving resource use efficiency in agriculture. To achieve this, Fordhook Giant Swiss chard was grown over two cropping seasons between February and November 2019 at the Ukulinga Research Farm in Mkondeni, Pietermaritzburg. The main factor was the growing method. The sub-factors were light provision and nutrient solution concentration. The hydroponic structures had a significantly higher land use efficiency than the plant pot setup (3 $041.05 \mathrm{~g} . \mathrm{m}^{-2}$ vs $405.89 \mathrm{~g} . \mathrm{m}^{-2}$ in cropping season one (CS1), and 3106.41 g.m $\mathrm{m}^{-2}$ vs 464.53 g.m $\mathrm{m}^{-2}$ in CS2), $\mathrm{p}<0.0005$. The crop water productivity of the hydroponic structures was significantly higher than that of the plant pot setup (8.45 g.L $\mathrm{L}^{-1}$ vs $5.72 \mathrm{~g} . \mathrm{L}^{-1}$ in CS L and 8.44 g.L $\mathrm{L}^{-1}$ vs $6.59 \mathrm{~g} . \mathrm{L}^{-1}$ in CS2), p < 0.0005 in CS1 and $\mathrm{p}=0.014$ in CS2. The energy use efficiency of plants grown hydroponically under sunlight $\left(104.25 \mathrm{~g}^{\mathrm{KWWh}} \mathrm{KW}^{-1} \mathrm{CS} 1 \mathrm{and}^{103.43}\right.$ g. $\mathrm{KWh}^{-1}$ in CS2) was significantly higher than that of plants grown hydroponically under grow lights $\left(12.30 \mathrm{~g} . \mathrm{KWh}^{-1} \mathrm{in} \mathrm{CS} 1 \mathrm{and}^{-1}\right.$


$9.29 \mathrm{~g}$. $\mathrm{KWh}^{-1}$ in CS2), $\mathrm{p}<0.0005$. The vertical hydroponic structures had higher resource use efficiencies than soil planting. The research showed that small-scale hydroponic structures can be used to improve agricultural productivity. (C) 2022 Friends Science Publishers
\end{abstract}

Keywords: Vertical hydroponics; Resource use efficiency; Land use efficiency; Crop water productivity; Energy use efficiency

\section{Introduction}

Vertical farming is a method of farming where fungi, plants, animals and other life forms are cultivated by artificially stacking them vertically (Banerjee and Adenaeuer 2014). Eigenbrod and Gruda (2015) presented vertical farming on a large scale as a technique that can be used to improve agricultural productivity. Vertical farming is conducted under controlled conditions. The elimination of natural, thus unpredictable, conditions eradicate weather-related plant damage and facilitates season-independent crop production. However, several challenges will be encountered with the establishment of large-scale commercial vertical farms. The highly controlled environments will require costly precision control and monitoring. Consequently, vertical farms will have high energy- and skilled labor requirements. Jenkins (2018) questioned the sustainability of vertical farms, proposing that the high energy requirements may be counterproductive to emission reduction. These limitations may deter current and potential producers from moving away from conventional farming systems (Çİçekli 2013;
Banerjee and Adenaeuer 2014; Sarkar and Majumder 2015). Barbosa et al. (2015) suggested that, in place of expensive large-scale hydroponic systems, simplified hydroponics could be used for food production as they are able to produce up to three or four times more crops than conventional agriculture on an area basis. The performance of hydroponic systems can be improved by making use of small-scale vertical farming structures. These structures would maximize the efficiency which with space is used by making use of multiple growing levels. Small-scale vertical farming systems can contribute to increasing land use efficiency (LUE) by extending food production into the vertical plane, thus increasing yield per unit area.

Currently, there is limited quantitative research on the applicability of small-scale vertical farming systems in replacing conventional farming systems for future food production. Cho (2015) attributed this information deficiency to the short time span that vertical farms have been in operation. The owners had no incentive to collect and record operational data. Furthermore, due to competitive reasons, owners are reluctant to reveal too much information.

To cite this paper: Buyeye Z, G Lagerwall, A Senzanje, A Clulow, S Sibanda (2022). Evaluation of the resource use efficiencies of small-scale vertical hydroponic structures against growing plants in soil. Intl J Agric Biol 27:60-68 
Therefore, the objective of this research was to assess the resource use efficiency of small-scale vertical hydroponic structures compared to ground-based planting, in terms of land-, water- and energy-use efficiency, under sunlight and Light Emitting Diode (LED) grow lights. This was done to evaluate the potential use of small-scale vertical farming systems in agricultural intensification. The motivation for investigating small-scale vertical farming structures was that they would be able to produce more yield per unit area than soil growth with lower energy requirements than large-scale vertical farming systems.

It was postulated that the resource use efficiencies of vertical hydroponic structures under sunlight and LED grow lights would not differ from the resource use efficiencies of soil planting under sunlight and LED grow lights. The results obtained in the study disproved the null hypothesis. The vertical hydroponic structures had higher resource use efficiencies than soil planting. Small-scale vertical hydroponic structures have higher agricultural productivity than conventional farming, in terms of land, water and energy use.

\section{Materials and Methods}

\section{Experimental details and treatments}

A hydroponic vertical design was selected for this study. Swiss chard (Spinacea oleracea) was selected because it is a highly nutritious leafy vegetable and it can be grown in a wide range of hydroponic systems (Parkell et al. 2016). The trials were conducted inside the Engineering Practicals Laboratory at the Ukulinga Research Farm in Pietermaritzburg over two cropping seasons, one starting in February and ending in March, and the other starting in October and ending in November 2020.

\section{Experimental design}

The study made use of a randomized complete block design and consisted of three factors, each comprising two levels. The main factor was the growing method: planting in soil vs vertical hydroponics. The first sub-factor was light provision: natural sunlight vs artificial light. Red blue LED strip grow lights were used in a ratio of $4: 1$, thus providing light in the photosynthetically active radiation range. The light was provided at an intensity of 260 $\mu \mathrm{mol} . \mathrm{m}^{-2} . \mathrm{s}^{-1}$ for an $18 \mathrm{~h}$ photoperiod as proposed by (Kang et al. 2013). The second sub-factor was the concentration of the nutrient solution. Concentration level one $(\mathrm{C} 1)$ was 1.4 g. $\mathrm{L}^{-1}$ and concentration level two (C2) was 1.9 g. $\mathrm{L}^{-1}$ (Kumari et al. 2018). These concentration levels were used to observe whether there would be significant variation between the treatments across low and high nutrient concentrations. The treatments were replicated four times.

Potting soil and plant pots were used for the soilgrown plants. A total 160 plant pots were used for plants for each lighting condition, each plant pot carried one plant. Within each lighting condition, 80 plant pots were irrigated with $\mathrm{C} 1$ and the remaining 80 were irrigated with $\mathrm{C} 2$. The plant pots were marked to indicate which would be irrigated with which concentration level. The marked pots were then placed randomly within each light treatment. The total area occupied by the plant pots was $5 \mathrm{~m}^{2}$ for each lighting setup. The pots were kept in position after sampling to not change total area occupied by the plant pots.

For the vertical setup, $1200 \mathrm{~mm}$ long polyvinyl chlorine (PVC) pipes with a $120 \mathrm{~mm}$ diameter were attached to a frame made of $38 \times 38 \times 3 \mathrm{~mm}$ steel sections. In each lighting treatment, the vertical hydroponic structures carried a total of 160 plants. Each PVC pipe column carried twenty plants. For each lighting treatment, each structure had a 45L reservoir, where a $2 \mathrm{~m}$ (maximum head), 1200 L. ${ }^{-1}$ (maximum flow rate) submersible fountain pump was used to recirculate the nutrient solution. In the first reservoir, the nutrient solution concentration was $\mathrm{C} 1$ and in the second, it was C2. Micro-sprayers were used to deliver the nutrient solution to the plant roots. The nutrient solution flowed down to the bottom of the pipes by gravity, where it was collected in gutters and returned to the reservoir. The plants were secured in $50 \mathrm{~mL}$ net pots, with $55 \mathrm{~mm}$ top- and $35 \mathrm{~mm}$ bottom diameters and a $52 \mathrm{~mm}$ height. Each net pot carried one plant. Expanded clay pellets were used as the growing medium.

\section{Fertigation and irrigation}

The nutrient solution selected for the experiment was Nutrifeed by Stark Aryes (Xego et al. 2016). This nutrient solution comprised the following macro- and micronutrients: Nitrogen $(6.5 \%)$, Phosphorus $(2.7 \%)$, Potassium (13\%), Calcium (7.0\%), Magnesium (2.2\%), Sulphur (7.5\%) and Iron, Manganese, Boron, Zinc, Copper and Molybdenum. Trichoderma was used in conjunction with the nutrient solution at the beginning of transplanting as biological control, as it can protect against diseases such as leaf spot and wilt in leafy vegetables (Bhale et al. 2012). Diatomaceous earth was coated bi-weekly onto the plants to control pests such as aphids and thrips (Buss and Brown 2006). The Irrigation Design Manual (Burger et al. 2003) was used to calculate irrigation requirements of the soil grown plants. It was determined that the plants would need to be irrigated with $5 \mathrm{~mm}$ of water every 3 days.

The nutrient solution was applied with every second irrigation. The TEROS 21 soil water potential meter (METER Group, Inc. USA) with $\pm 10 \%$ accuracy (Eliades et al. 2018) in conjunction with a Decagon Pro Check readout device (Bart et al. 2015) were used to monitor soil moisture to ensure that the plants were not under- or over irrigated. For the hydroponic structures, the nutrient solution was replenished every week. When the nutrient solution was replenished, the solution from the previous week was discarded to prevent the pumps from being clogged by the 
nutrient solution precipitate. An Eco Testr EC meter (Stanley et al. 2014) with a $\pm 1 \%$ accuracy (Eutech Intsruments, Singapore) was used to monitor the electrical conductivity to ensure that it was within recommended values of 1.5 and $2.5 \mathrm{dS} . \mathrm{m}^{-1}$ (Kumari et al. 2018). When the solution was above this range, it would be diluted with water. When it fell below these values, more nutrient solution would be added. The $\mathrm{pH}$ was also checked to ensure that it ranged between 5.5 and 6.5 as recommended for hydroponic systems (Sardare and Admane 2013). In cases where these values were exceeded, a $\mathrm{pH}$ up/down solution was used to return the solution to permissible values.

\section{Data collection}

The area occupied by each treatment was determined using a measuring tape. Dry matter output per unit area was used as a measure of the land use efficiency. The land use efficiency (LUE) was determined using Equation 1.

$$
L U E=\frac{N_{T}}{A} \times w_{D}
$$

Where $L U E$ is the land use efficiency $\left(\mathrm{g} \cdot \mathrm{m}^{-2}\right), N_{T}$ is the total number of plants, $A$ is the area occupied by the growing system $\left(\mathrm{m}^{2}\right)$ and $W_{D}$ is the plant dry weight $(\mathrm{g})$. The water use per plant was determined using Equation 2. The dry matter produced per liter of total water used (g.L $\left.\mathrm{L}^{-1}\right)$ was used as a measure of crop water productivity (CWP).

$$
C W P=\frac{N_{T}}{w_{T}} \times w_{D}
$$

Where $C W P P$ is the average crop water productivity $\left(\mathrm{g} . \mathrm{L}^{-1}\right)$ and $W_{T}$ is the total water used for irrigation during growing period (1). For the hydroponic systems under sunlight, the pump energy consumption was calculated to determine the energy use efficiency (EUE). For the hydroponic systems under sunlight, the pump energy consumption was calculated to determine the energy use efficiency (EUE). For the hydroponic system under LED grow lights, the pump and grow lights energy consumption were calculated to determine the EUE. For the soil setup under grow lights, the lights' electricity consumption was used to determine the EUE.

Equation 3 was used to determine the EUE of the different treatments.

$$
E U E=\frac{N_{T}}{P \times t} \times w_{D}
$$

Where $E U E$ is the energy use efficiency $\left(\mathrm{g} . \mathrm{KWh}^{-1}\right), P_{\text {is }}$ the power rating of equipment $(\mathrm{KW})$ and ${ }^{t}$ is the total run time of equipment (hours).

\section{Data analysis}

An analysis of variation (ANOVA) at a $95 \%$ confidence interval using IBM SPSS Statistics 26 (Dytham 2011) was used to conduct statistical analysis of the results of two cropping seasons.

\section{Results}

This section presents the comparison of the resource use efficiencies (RUEs) of the different treatments. Land-, water-, and energy use efficiencies were used as measures of resource use efficiencies. The three-way interaction between the growing method, light provision and nutrient solution concentration level was not statistically significant for all the RUEs that were evaluated in the study. This was because the two-way interactions between the growing method and light provision did not differ significantly across the two levels of nutrient solution concentration for all the RUEs. Furthermore, the main effects of growing method and light provision did not differ significantly across the two levels of nutrient solution concentration. This result means that the level of nutrient solution concentration did not have a significant effect on the RUEs. Therefore, the interpretations of the results obtained in the study are admissible across recommended nutrient solution concentration levels.

\section{Land use efficiency}

There was a statistically significant difference between the LUE of plants grown hydroponically and those grown in soil, $\mathrm{p}<0.0005$ in both cropping seasons. The difference between the LUE of plants grown hydroponically under grow lights and plants grown in soil under grow lights was statistically significant, $\mathrm{p}<0.0005$. In both cropping seasons, the LUE of plants grown hydroponically under grow lights was significantly higher than that of plants grown hydroponically under sunlight, $\mathrm{p}<0.0005$. Even though both systems occupied the same space, thus producing the same number of plants per unit area, the dry mass per unit area of the plants grown hydroponically under grow lights was significantly higher than that of plants grown hydroponically under sunlight. Fig. 1 and 2 display the land use efficiencies for the different treatments in CS1 and CS2, respectively. The LUE of plants grown hydroponically under sunlight was significantly higher than that of plants grown in soil under LED grow lights, $\mathrm{p}<$ 0.0005 .

\section{Crop water productivity}

Plants grown hydroponically and those grown in soil used a comparable amount of water in terms of total water consumption over the growing period. This was because in the study, the nutrient solution used by the hydroponic systems was discarded weekly. This was done to prevent the pumps from being clogged by the nutrient solution that would collect at the bottom of the reservoir due to precipitation of salts in the nutrient solution. However, the 


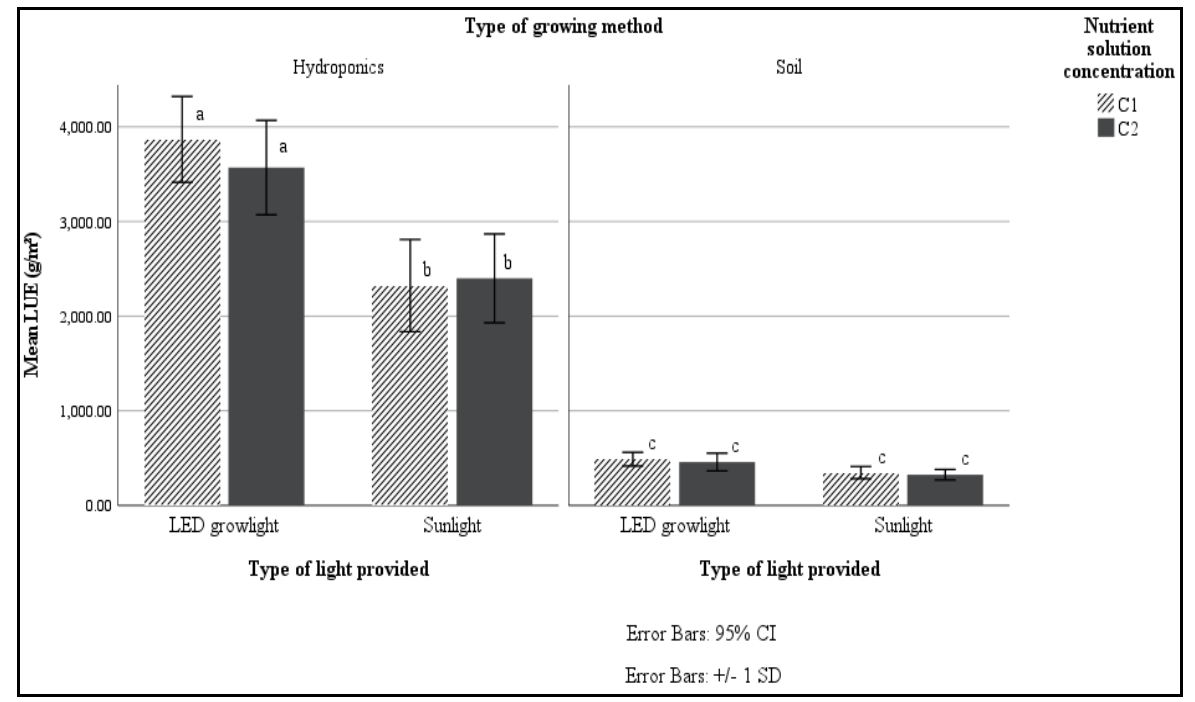

Fig. 1: The land use efficiency in $\mathrm{g} \cdot \mathrm{m}^{-2}$ of the different treatments in cropping season one. The same letters indicate that the difference was not statistically significant between the treatments at $\mathrm{P} \leq 0.05$

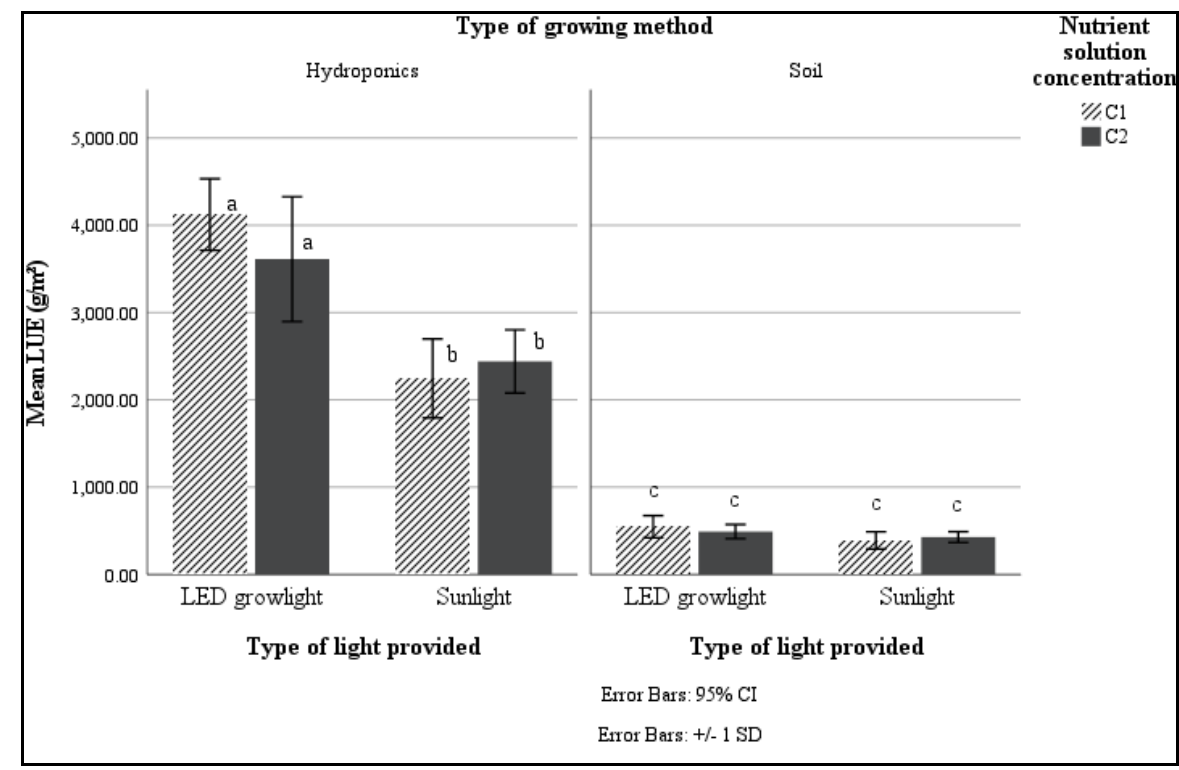

Fig. 2: The land use efficiency in g. $\mathrm{m}^{-2}$ of the different treatments in cropping season two. The same letters indicate that the difference was not statistically significant between the treatments at $\mathrm{P} \leq 0.05$

difference between the mean CWP of plants grown hydroponically and those grown in soil was statistically significant in both cropping seasons, $\mathrm{p}<0.0005$ in CS1 and in CS2, p = 0.014. Fig. 3 and 4 display the CWP for the treatments in CS1 and CS2, respectively.

Although the water consumption for both treatments was the same, there was a significant difference in both seasons ( $p<0.0005$ ) between the mean CWP of plants grown hydroponically under LED grow lights and plants grown hydroponically under sunlight. There was no significant difference between the CWP of plants grown hydroponically under sunlight and those grown in soil under grow lights, $\mathrm{p}=0.969$ in CS1 and $\mathrm{p}=0.099$ in CS2.

\section{Energy use efficiency}

The difference between the mean EUE between plants grown hydroponically under sunlight and those grown hydroponically under grow lights was statistically significant, $\mathrm{p}<0.0005$ in both cropping seasons. Fig. 5 displays the EUE for the plants grown hydroponically under the different light settings in CS1 and CS2.

The mean EUE of plants grown hydroponically under grow lights was significantly different from the mean EUE 


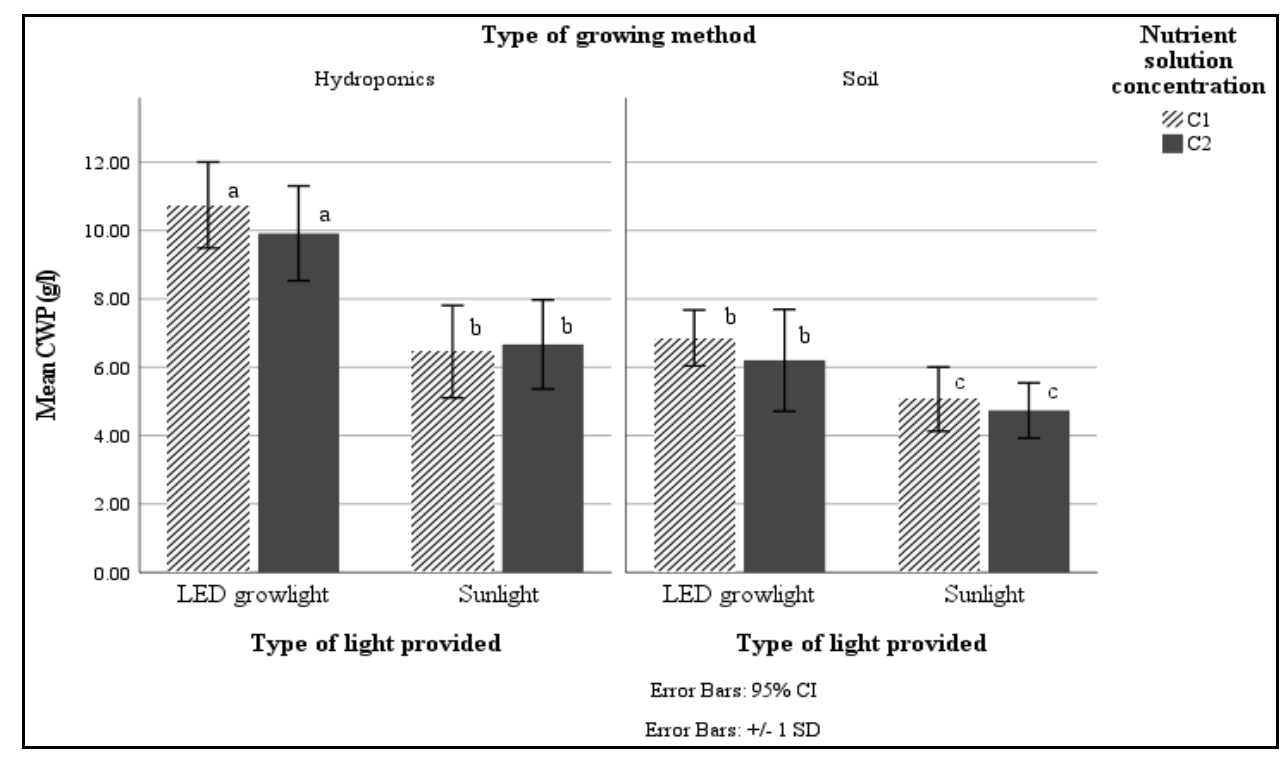

Fig. 3: The water use efficiency in $\mathrm{g} . \mathrm{L}^{-1}$ of the different treatments in cropping season one. The same letters indicate that the difference was not statistically significant between the treatments at $\mathrm{P} \leq 0.05$



Fig. 4: The water use efficiency in g. $\mathrm{L}^{-1}$ of the different treatments in cropping season two. The same letters indicate that the difference was not statistically significant between the treatments at $\mathrm{P} \leq 0.05$

of soil grown plants under grow lights, $\mathrm{p}=0.002$ in CS1 and $p=0.013$ in CS2. Fig. 6 displays the EUE of the plants grown hydroponically and those grown in soil under LED grow lights. There was a significant difference $(p<0.0005$ in both cropping seasons) between the EUE of plants grown hydroponically under sunlight and plants grown in soil under grow lights. Fig. 7 illustrates the EUE of the hydroponic system under sunlight and the soil system under grow lights.

\section{Discussion}

Use of the vertical plane enabled the hydroponic structures to occupy a smaller horizontal area whilst producing more plants per unit area. The vertical structures were able to produce 5 times more plants per unit area than the soil set up for both light treatments. This result is important because, with increasing food requirements and dwindling arable land, small-scale hydroponic vertical structures use 




Fig. 5: The energy use efficiency in g.KWh ${ }^{-1}$ of the plants grown hydroponically under different light treatments in cropping season one (CS1) and two (CS2). The same letters indicate that the difference was not statistically significant between the treatments at $\mathrm{P} \leq 0.05$

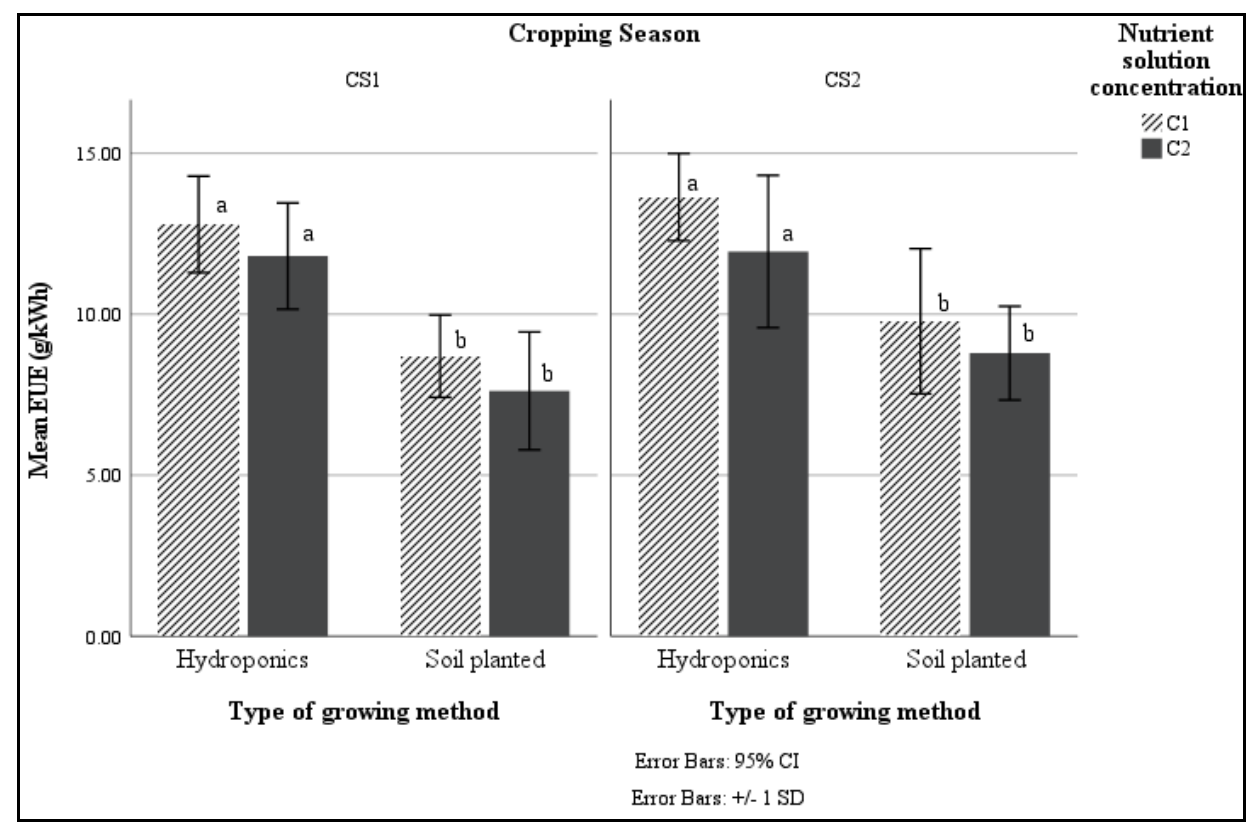

Fig. 6: The energy use efficiency in $\mathrm{g}$. $\mathrm{KWh}^{-1}$ of the different growing methods under LED grow lights in cropping season one (CS1) and two (CS2). The same letters indicate that the difference was not statistically significant between the treatments at $\mathrm{P} \leq 0.05$

occupied space more efficiently than conventional planting in soil. In contrast, Rufí-Salís et al. (2020) reported a much higher LUE for large-scale vertical farms, stating that such systems could have LUE values that are 12.5 - 25 times higher than the conventional greenhouse production of lettuce. However, the LUE of small-scale vertical farming structures could be increased by increasing column height. But factors, such as column stability, shading effects, ergonomics for planting/harvest time and ergonomics for maintenance would have to be considered before scaling up column sizes.
The addition of grow lights resulted in higher plant mass production. This is because grow lights produce controlled and more consistent radiation than sunlight. Unlike sunlight, the radiation from grow lights is not influenced by factors such as weather conditions. Additionally, artificial grow lights have the added benefit of providing a photoperiod that can be altered to suit plant needs. In the study, plants grown under grow lights had an $18 \mathrm{~h}$ photoperiod, whereas the photoperiod for plants grown under sunlight depended on when the sun rose and set.

The results indicate that when comparing hydroponic 




Fig. 7: The energy use efficiency in $\mathrm{g}$. $\mathrm{KWh}^{-1}$ of the different treatments in cropping season one (CS1) and two (CS2). The same letters indicate that the difference was not statistically significant between the treatments at $\mathrm{P} \leq 0.05$

systems under sunlight with plants grown in soil under grow lights, the use of the vertical plane outperforms the benefits associated with grow lights. This is because the vertical structures occupied a smaller horizontal area than the plant pots. Therefore, they produced more plants per unit area than the plants grown in soil under grow lights. This is an important result for controlled environmental agriculture (CEA) where grow lights are used to supplement sunlight during dark hours. Grow lights have been identified as one of the highest energy consumers in CEA. Therefore, this result suggests that vertical hydroponic structures could be an alternative to soil-based plant growth in cases where grow lights supplement sunlight, as they use space more efficiently.

In this study, it was observed that the leaf areas of plants grown hydroponically under sunlight decreased in size along the length of the columns from top to bottom. Due to sample number restrictions, it could not be determined whether this variation was significant. This appears to be a limitation that is inherent to column-type vertical farming structures, as Touliatos et al. (2016) noted similar trends for lettuce grown in vertical columns under metal halide lamps. In the study by Touliatos et al. (2016), the grow lights were placed above plants. However, in this undertaken study, the leaf area sizes did not vary along the column lengths of plants grown hydroponically under grow lights because the lights were placed in front of the structures. This limitation, therefore, only poses a restriction for increasing column height for plants grown under sunlight or in cases where grow lights are placed above the columns.

Barbosa et al. (2015) reported that hydroponically- and soil-grown lettuce consumed a comparable volume of water, but the hydroponically grown lettuce consumed less water per plant or, inversely, produced more yield per liter of water than the soil system. A similar result was found in this study. This can be attributed to the fact that, in hydroponic systems, a higher fraction of the supplied water is allocated to plant production than in soil systems. In soil systems, some of the water supplied is lost to the soil environment surrounding the plant. In hydroponic systems, because the nutrient solution is collected at the roots and recirculated, there is minimal water loss to the surroundings. This is an important finding for agriculture because freshwater availability is an important concern. These results show that vertical hydroponic structures produce significantly higher yields than soil planting from the same volume of water.

The mean CWP of the vertical hydroponic structures could further be improved if the 'old' nutrient solution was not discarded every week, as was done in the study, but rather recovered and reused. Rufí-Salís et al. (2020) investigated techniques for nutrient solution recovery in hydroponics and found that direct leachate recirculation was the best option in terms of nutrient solution re-use, and it had a lower carbon footprint than the other options investigated. In this system, the recovered nutrient solution could be filtered and sterilized. The remaining nutrients would then be analyzed to assess which nutrients needed to be re-added to meet plant requirements. Such a system would have a two-fold impact as it would not only decrease the amount of water added to the system, but it would also decrease the overall amount of nutrients supplied as well.

The presence of LED grow lights improved the 
hydroponic system's yield production per liter of water consumed. In their study of greenhouse tomatoes, Li et al. (2019) also found that plants grown under supplementary LED lighting had a higher CWP than plants grown under sunlight, even though water consumption was similar. The higher CWP by the hydroponic system under grow lights was because the LED grow lights enhanced plant photosynthesis, thereby increasing CWP without changing water consumption (Li et al. 2019).

Despite the resulting increase in LUE and CWP, indoor lighting has been identified as one of the largest energy consumers in CEA (Sparks 2016). Barbosa et al. (2015) documented that the large-scale hydroponic production of lettuce can require 82 times or more energy per kilogram than conventional lettuce production. The high energy consumption in this study was because the grow lights operated for $18 \mathrm{~h}$ a day to meet the recommended photoperiod for plants. Although this has been proven to be beneficial in terms of LUE and CWP, the large difference in EUE is a concern, especially when the aim of vertical farming is to minimize negative environmental impacts.

Even though the hydroponic system under grow lights had additional energy consumption from the pump, its EUE was still significantly higher than that of the soil grown plants under grow lights. This meant that, despite the vertical hydroponic system under grow lights having higher energy consumption than soil-based growth under grow lights, the hydroponic system was more productive in terms of EUE. Use of the vertical plane in conjunction with water recirculation resulted in a more efficient use of energy. This result is important for soil-based CEA where artificial grow lights are used to completely replace sunlight. Since these types of CEA applications already need artificial grow light, replacing soil plant growth with small-scale vertical hydroponic systems would result in more efficient use of energy.

Whilst the energy consumption of the grow lights resulted in low EUE for both the hydroponic and the plant pot systems, the study demonstrated that the presence of grow lights can improve resource use efficiency. Pennisi et al. (2019) also reported that use of grow lights can increase the overall resource use efficiency of plant production. In the LUE graphs and CWP graphs, the difference between the light treatments is more distinct in the hydroponics treatment than in the soil treatment. This observation suggests that hydroponic systems use LED grow lights more efficiently than growing plants in soil.

There are several ways in which the energy consumption of systems that use grow lights could be decreased. In regions with sufficient sunlight radiation, these systems could be designed such that grow lights are used seasonally or during times of low radiation. This presents an opportunity for the development of affordable devices that can detect radiation and produce instantaneous results about whether the use of grow lights is necessary at a certain period.
Furthermore, grow lights can be used to mitigate the variance of plant size along the length of columns in vertical hydroponic systems. In such systems, grow lights can be applied to the lower sections to supplement sunlight. Another alternative would be to use grow lights for a shorter photoperiod. That is, to have the grow lights operate for a few hours during dark hours to extend time for photosynthesis whilst reducing electricity consumption. For example, Frąszczak (2013) found that exposing dill plants to red LED light or white light at the end of the night for 30 min stimulated plant growth. Therefore, there are several options that can be explored where LED grow lights can be used in such a manner that optimizes plant growth, whilst decreasing energy consumption in vertical hydroponics.

\section{Conclusion}

Research presents vertical farming as a possible solution to the challenges associated with conventional farming. Use of the vertical plane and artificial inputs has been stated to improve yield quantities and qualities. However, thus far, there has been a deficit of information on whether yield improvements are achieved at a greater input cost than the conventional growth of plants in soil. This study has contributed to increasing knowledge on the resource use efficiencies of small-scale vertical hydroponic systems. The research conducted has proven that small-scale vertical hydroponic structures use resources more efficiently than growing plants in soil under LED grow lights as well as under sunlight for recommended nutrient solution concentrations.

\section{Acknowledgements}

The first author acknowledges the financial sponsorship from Agricultural Research Council and the Department of Science and Technology, South Africa.

\section{Author Contributions}

ZB conceptualized the work, collected and interpreted the data, drafted and conducted critical revision of the article. GL and AS contributed to the conceptualization of the work and critically revised the article. AC critically revised the article, and SS contributed to the conceptualizing of the work.

\section{Conflicts of Interest}

The authors hereby declare that they do not have competing financial interests or any relationships of a personal nature that could have had influence on the work reported in this paper.

\section{Ethics Approval}

The experiments conducted in the study were not 
conducted on animal or human subjects. Therefore, ethics approval was not required for the study.

\section{Funding Source}

The research was made possible by funding from The Department of Science and Technology through The Agricukltural Research Council.

\section{References}

Banerjee C, L Adenaeuer (2014). Up, up and away! The economics of vertical farming. J Agric Stud 2:40-60

Barbosa GL, FDA Gadelha, N Kublik, A Proctor, L Reichelm, E Weissinger, GM Wohlleb, RU Halden (2015). Comparison of Land, Water, and Energy Requirements of Lettuce Grown Using Hydroponic vs. Conventional Agricultural Methods. Intl J Environ Res Pub Health 12:6879-6891

Bart D, T Davenport, Q Carpenter (2015). Stress and land-use legacies alter the relationship between invasive-and native-plant richness. $J$ Veg Sci 26:80-88

Bhale U, M Ambuse, V Chatage, J Rajkonda (2012). Bioefficacy of Trichoderma isolates against pathogenic fungi inciting spinach (Spinacea oleracea L.). J Biopest 5:222

Burger J, P Heyns, E Hoffman, E Kleynhans, F Koegelenberg, M Lategan, D Mulder, H Smal, C Stimie, W Uys, F van der Merve, I van der Stoep, P Viljoen (2003). Irrigation Design Manual. Agricultural Research Council - Institute for Agricultural Engineering, Pretoria, South Africa

BussE, S Brown (2006). Natural Productsfor Insect Management. Available at: https://www.researchgate.net/profile/Eileen_Buss/publication/237391 484

Natural_Products_for_Insect_Pest_Management1/links/00b4952a5db ef7e2b4000000.pdf (Accessed: 02 May 2020)

Cho $R$ (2015). How sustainable is vertical farming? Available at: https://phys.org/print369046891.html (Accessed: 10 February 2018)

Çiçeklİ M (2013). Vertical farming. Ege Üniversitesi Ziraat Fakültesi Dergisi Special Issue: 383-388

Dytham C (2011). Choosing and Using Statistics: A Biologist's Guide. Wiley-Black, West Sussex, United Kingdom

Eigenbrod C, N Gruda (2015). Urban vegetable for food security in cities. A review. Agron Sust Dev 35:483-498

Eliades M, A Bruggeman, H Djuma, MW Lubczynski (2018). Tree water dynamics in a semi-arid, Pinus brutia forest. Water 10:1039-1060
Frąszczak B (2013). Effect of short-term exposure to red and blue light on dill plants growth. Hortic Sci 40:177-185

Jenkins D (2018). Rise to the Challenge Vertical Farming within the Urban Environment. MSc Dissertation, Architecture, Unitec Institute of Technology, Auckland, New Zealand

Kang JH, S KrishnaKumar, SLS Atulba, BR Jeong, SJ Hwang (2013). Light intensity and photoperiod influence the growth and development of hydroponically grown leaf lettuce in a closed-type plant factory system. Hortic Environ Biotech 54:501-509

Kumari S, P Pradhan, R Yadav, S Kumar (2018). Hydroponic techniques: A soilless cultivation in agriculture. $J$ Pharmacog Phytochem 7:1886-1891

Li Q, Y Liu, S Tian, Z Liang, S Li, Y Li, M Wei, D Zhang (2019). Effect of supplemental lighting on water transport, photosynthetic carbon gain and water use efficiency in greenhouse tomato. Sci Hortic 256:108630

Parkell NB, RC Hochmuth, WL Laughlin (2016). Leafy Greens in Hydroponics and Protected Culture in Florida. Institute of Food and Agricultural Sciences. Available at: https://growables.com/information/documents/HydroLeafyGreenUF. pdf (Accessed: 19 June 2017)

Pennisi G, F Orsini, S Blasioli, A Cellini, A Crepaldi, I Braschi, F Spinelli, S Nicola, JA Fernandez, C Stanghellini (2019). Resource use efficiency of indoor lettuce (Lactuca sativa L.) cultivation as affected by red: blue ratio provided by LED lighting. Sci Rep 9:1-11

Rufí-Salís M, MJ Calvo, A Petit-Boix, G Villalba, X Gabarrell (2020). Exploring nutrient recovery from hydroponics in urban agriculture: An environmental assessment. Resourc, Conserv Recycl 155:104683

Sardare MMD, MSV Admane (2013). A review on plant without soilhydroponics. Intl J Res Eng Technol 2:299-305

Sarkar A,M Majumder (2015). Opportunities and Challenges in Sustainability of Vertical Eco-Farming: A Review. J Adv Agric Tech 2:98-105

Sparks RE (2016). Mapping and analyzing energy use and efficiency in a modified hydroponic shipping container. Unpublished Dissertation thesis, Engineering, Purdue University, West Lafayette, USA

Stanley JN, DW Lamb, G Falzon, DA Schneider (2014). Apparent electrical conductivity (ECa) as a surrogate for neutron probe counts to measure soil moisture content in heavy clay soils (Vertosols). Soil Res 52:373-378

Touliatos D, IC Dodd, M McAinsh (2016). Vertical farming increases lettuce yield per unit area compared to conventional horizontal hydroponics. Food Ener Sec 5:184-191

Xego S, L Kambizi, F Nchu (2016). Threatened medicinal plants of South Africa: case of the family Hyacinthaceae. Afr J Trad Compl Alt Med 13:169-180 